Esta obra está sob o direito de Licença Creative Commons Atribuição 4.0 Internacional.

\title{
EDUCAÇÃO EM TEMPO DE PANDEMIA
}

Nadieje Maria Soares da Silva ${ }^{1}$

\section{RESUMO}

Este artigo foi motivado pelo desejo da autora em aprofundar seu conhecimento sobre a pandemia para a educação, cujo objetivo é estudar os efeitos do Novo Coronavírus para a sociedade e particularmente para educação, a relação professor-aluno, a pratica e a realização de aulas remotas para o ensino aprendizagem, buscando entender problemáticas como: até que ponto o uso dos dispositivos digitais contribui ou reduz a ação da aprendizagem? As aulas remotas correspondem efetivamente às aulas presenciais, a uma aprendizagem significativa? Foi o que se buscou demonstrar no percurso deste artigo, onde também se inclui o papel da escola com entidade eminentemente educativa. Adota como metodologia a pesquisa bibliográfica tendo como suporte teórico autores como: Barbosa, Viegas e Batista (2020), Dias e Pinto (2019), Vieira e Ricci (2020), entre outros. Sustenta, em síntese, que a educação é o bem maior do ser humano e que a escola e professores devem ouvir e compreender os reclamos dos alunos para então dar soluções para facilitar o aprendizado e a educação com aulas remotas.

Palavras-chave: Pandemia. Aluno-professor. Aprendizagem. Função social da escola.

\footnotetext{
1. Mestra e doutoranda da Universidad Autônoma de Asuncion - UAA
} 


\section{INTRODUÇÃO}

Motivado pelo interesse da autora em compreender com maior profundidade a relação educação e pandemia, este artigo tem como objetivo estudar os efeitos da pandemia na educação, a relação professor-aluno, a prática e a realidade das aulas remotas para o ensino-aprendizagem.

Tendo como problemática a interferência da pandemia do novo coronavírus, buscando responder questões como: até que ponto o uso dos dispositivos digitais contribui ou reduz a ação da aprendizagem? As aulas remotas correspondem efetivamente às aulas presenciais? As aulas remotas levam a uma aprendizagem significativa? É o que se pretende responder durante $o$ desenvolver deste artigo, assim como qual o papel da escola na conscientização da comunidade escolar no contexto da pandemia.

Adotando como metodologia a pesquisa bibliográfica com suporte em autores como: Anastasiou (2002), Barbosa; Viegas e Batista (2020), Dias e Pinto (2019), Silveira (2020), Vieira e Ricci (2020), a partir do entendimento de que toda pesquisa, conforme pontuam Lankshear \& Knobel (2008, p.32), “é guiada por estruturas teóricas e conceituais circunscrevendo o curso e o campo visualizado o levantamento de informações de qualidade pertinente às questões decorrentes e aos propósitos do pesquisador, de forma coerente".

Trata sobre o papel da escola em período de pandemia no contexto da sociedade e quais suas implicações para a educação brasileira e seus efeitos no ensino-aprendizagem e como se pode minimizar sua interferência na educação dentro da realidade educativa.

Fundamenta que a educação é o bem maior do ser humanos, ao tempo em que pontifica a realidade da pandemia para a escola e para a educação, configurando que o combate a pandemia é uma questão coletiva, enfatizando que o negacionismo à pandemia é um ato incivilizado, cabendo à escola assumir seu papel social, principalmente, no sentido de educar a comunidade escolar sobe as medidas para a prevenção do contágio pelo Covid-19.

Trata da preocupação da escola e dos professores sobre a prática didáticopedagógica, focando as dificuldades dos alunos, principalmente, de baixa renda sobre a aquisição de equipamentos, dificuldade de acesso às mídias digitais, agravada especialmente para os alunos da zona rural, trazendo também à tona a preocupação com a preparação dos professores quanto ao uso de dispositivo para as aulas remotas. Enfim, mostra que 
embora as aulas remotas sejam uma alternativa para a continuidade do processo educativo, não substitui com eficiência as aulas presenciais.

\section{METODOLOGIA}

O presente estudo se desenvolveu por meio de uma revisão de literatura de natureza qualitativa. Para a produção desta pesquisa inicialmente foi estabelecida identificação do tema. EDUCAÇÃO EM TEMPO DE PANDEMIA.

Para as fontes adquiridas foram utilizadas bases de dados online por meio dos descritores utilizados na pesquisa. A fim de determinar as informações relevantes que seriam extraídas na revisão.

\section{CONTEXTO}

A pandemia é um fenômeno que não tem apenas atingido a sociedade, mas, em particular à educação forçando as escolas a mudar a rotina, exigindo trocar o sistema presencial por aulas remotas com o uso da tecnologia, requerendo mudanças no jeito de ensinar e aprender, mudando o comportamento do professor e do aluno,

Nesse contexto, é preciso pensar a maneira de ensinar, o que, sem dúvida, requer também repensar o planejamento didático-pedagógico para atender satisfatoriamente a demanda dos alunos, da escola e da própria sociedade, levando em conta que a educação é fator crítico para o desenvolvimento dos alunos e das comunidades onde a escola está inserida.

$$
\text { O fato é que em razão da }
$$
pandemia, o Ministério da Educação, através da portaria ${ }^{\circ} 343$ de 17 de março de 2020, se manifesta orientando a substituição das aulas presenciais por aulas remotas enquanto durar a pandemia do novo coronavírus, porém, a princípio, somente para aulas de nível superior do sistema federal de educação.

Seguindo o mesmo caminho, o Conselho Nacional de Educação pela portaria $n^{\circ} 345 / 2020$, estende as digitais para a rede de ensino, em todos os níveis, etapas e modalidades, cujo argumento é de que o sistema de educação brasileiro, precisa ser reorganizado em função da pandemia, levando, por decorrência os Estados e Municípios a adotarem a mesma medida, o que também exigira a reorganização do calendário escolar.

Acompanhando essas medidas o CNC - Conselho Nacional de Educação, edita um parecer favorável a atividades pedagógicas remotas, sobretudo, no sentido de adequar a carga horária mínima em função da pandemia, que homologado pelo Ministério da Educação, orienta a prática pedagógica, levando em consideração o 
distanciamento social, contudo, não considerando as dificuldades que muitos alunos têm dificuldade de acesso à Internet, o que, sem dúvida, prejudicará a aprendizagem desses alunos.

Recomenda, por outro lado, que para satisfazer a carga horária mínima determinada pela Lei de Diretrizes e Bases - LDB, as escolas podem estabelecer a carga horária no fim do período da pandemia, ampliar a carga horária diária com a realização de atividades pedagógicas não presenciais no retorno das atividades presenciais, garantindo, segundo Martins e Almeida (2020), por meio de atividades não presenciais o fluxo 'normal' das atividades escolares, o que na opinião das autoras prejudica alguns grupos sociais que não dispõem de aparatado tecnológico,

O fato é que praticamente o ensino presencial tornou-se ensino a distância, para muitos alunos e professores um momento desafiador. Para os alunos por que muitos têm dificuldade de acessar a Internet e para os professores por ter que reinventar sua maneira de dar aula, às vezes, assumindo a função de tutores, visto que muito alunos e até mesmo professores não sabem o que fazer. Ficam perdidos em meio ao uso das tecnologias, tendo que se readaptar ao processo de ensino- aprendizagem, além de aumentar a demanda de tarefas e adaptar o conteúdo à nova realidade.

Essa situação leva forçosamente as escolas e os professores a elaboração de um plano de estudo subsidiário para apoiar o aluno na ação educacional e, não raramente, orientar o aluno quanto o uso das plataformas digitais, devendo-se considerar que nem sempre alunos e professores dominam os dispositivos impostos pela escola, obrigando professores e alunos a utilizarem aplicativos desconhecidos e às vezes até inadequados para o uso da aprendizagem, desmotivando, por conseguinte, alunos e professores.

Em síntese, a pandemia do COVID-19, embora traga malefícios para a sociedade, tem sido uma oportunidade para se (re) significar o conceito e a prática pedagógica, de se reaprender e inovar práticas educativas, mesmos sabendo-se que o ensino remoto não substitui a interação do relacionamento professor-aluno, que é importante para a aprendizagem e o desenvolvimento do aluno.

\section{EDUCAÇÃO VERSUS PANDEMIA - COVID-19}

Segundo a Organização das Nações Unidas para a Educação, Ciência e Cultura - UNESCO (2020), a 
pandemia atingiu $90 \%$ dos estudantes de todo o mundo, o que naturalmente se aplica ao Brasil, implicando na suspensão de aulas presenciais em todo o sistema educacional brasileiro, o que também poderá trazer consequência danosas não só para os alunos e as escolas, mas, também para a economia que sofre com o desemprego e a falta de perspectiva de retomada a normalidade da economia, o que por certo contribuirá para o aumento da desigualdade social e exclusão de alunos na escola.

Isto, por sua vez, requer políticas públicas eficientes, especialmente para a educação, para pelo menos amenizar, segundo ainda a UNESCO, a queda da aprendizagem que poderá arrastar-se por décadas, dificultando, entre outros aspectos, a economia e a evolução da educação, exigindo a reorganização do calendário escolar e das atividades acadêmicas, adequando as estruturas dos cursos para que o prejuízo educacional seja o menor possível.

Há, contudo, de se perceber que a educação remota, ou seja, a distância, de certa forma prejudica o desenvolvimento do aluno, notadamente, porque uma grande parte dos dispõe dos equipamentos necessário e até mesmo de uso da Internet de qualidade, o que, naturalmente contribuirá para a involução da educação em todos os seus níveis e modalidades, requerendo se repensar a educação principalmente no futuro.

A realidade é que diante da pandemia, muitos professores tiveram que se reinventar, repensar sua prática didático-pedagógica e aprender, segundo Dias (2020), a utilizar as plataformas digitais, assim como avaliar os alunos a distância e adequar os materiais pedagógicos, sobretudo, na tentativa de amenizar as dificuldades dos alunos, fazendo o possível para facilitar e garantir a qualidade do ensinoaprendizagem, ajustando a atividade curricular às necessidades do aluno.

É imprescindível, por outro lado, minimizar o impacto psicológico que a pandemia causa nos alunos e professores, cabendo à escola o papel de orientar quanto a prevenção da pandemia, o que não deixa de ser um ato educativo que o aluno pode compartilhar com seus familiares e amigos, o que em outras palavras é um ato de resiliência, ou seja, de resistir ao avanço da pandemia pela precaução e respeito às medidas restritivas que tem como fim evitar o contágio pelo corona vírus.

Deve-se compreender, conforme aponta Cavalcante (2007), que o homem é o objeto último da educação e a sociedade e o seu objetivo, a 
conservação da transformação social e confronto da mesma com a sociedade.

Nessa perspectiva, pode-se afirmar que este momento, é, sem dúvida, o momento de educar e transformar os hábitos da sociedade para enfrentar a pandemia, o que evidentemente é um ato educativo que pode levar a sociedade a um controle da corona vírus, compreendendo-se que a educação é um processo para intervir no todo social. Um instrumento para mediar a prática social, como o isolamento social, por exemplo.

Nessa visão, é possível se entender que o papel da escola no contexto da pandemia, é se organizar para superar as dificuldades dos alunos, dando-lhe o poder de refletir, sendo capaz de compreender a realidade e se tornar um multiplicador sobre a situação do covid-19, inspirando outras pessoas a se cuidar e tomar consciência de que combater a pandemia é um dever e um direito de todo cidadão, incluindo os grupos relacionais como família e toda comunidade de convivência dentro e fora do seio da escola.

Diante da pandemia a escola deve ampliar seu relacionamento com as famílias, redefinindo o comportamento dos alunos e dos professores, sendo ética, para motivar seus profissionais a superar os limites causados pela pandemia e evitar que a desmotivação se prolongue.

E escola precisa então preparar seu contingente humano para entender as mudanças e evitar estresse que atinge a autoestima, o comportamento profissional e suas relações com a escola e com os alunos, podendo também atingir a família dos alunos, levando em conta que os profissionais de educação são agentes de mudanças, que precisão respaldar a aprendizagem e a educação de forma holística, ou seja, como um todo e ter respaldo da sociedade onde está inserida.

Em momento de pandemia, especialmente, faz-se necessário que escola e família formem uma parceria consistente, notadamente em função das transformações ocorridas com o COVID-19, abrindo um canal de comunicação direto para através do diálogo combater a pandemia e conscientizar os alunos e a sociedade sobre os riscos e as consequências desse terrível mal, não permitindo que o negacionismo predomine sobre as orientações científicas a respeito dos cuidados com o vírus, evitando inversão de valores, pois, não aceitar que a pandemia é um fenômeno nocivo para as pessoas e para sociedade, é investir no descaso, desmerecer a importância científica da medicina. 
É importante que escola e família trabalhem em conjunto para, pelo menos, minimizar o desconforto provocado pela pandemia, observando que as questões de prevenção é um ato de cidadania, de educação. Cabe a escola e a família dar suporte ao aluno e à educação respaldada pelo comportamento da escola e da família, sendo fundamental que os pais cumpram seu dever de educar e advertir a sociedade sobre os riscos da epidemia, ajudando a construir uma cultura de respeito aos riscos e a vulnerabilidade diante do vírus.

A escola no contexto da pandemia deve entender que a família é uma fonte de educação dos filhos, e por isso deve com ela interagir se influenciando mutuamente, sendo também responsável pela saúde e segurança do aluno dentro da realidade social, devendo entender segundo Di Santos (2007), quanto melhor for a parceria entre escola e família, mais positivo e significativos serão os resultados na formação e educação do sujeito.

Todavia, há de se conceber que no contexto da pandemia os pais também podem ter dificuldades de operar os aplicativos remotos, o que torna difícil ajudar o estudante, levando ao desgaste da educação, interferindo no desempenho e qualidade educativa, sendo de competência de a escola pensar na saúde dos alunos e professores que nesse momento de pandemia podem estar vulneráveis e expostos aos perigos expostos pelo vírus, e que segundo Maia e Dias (2020), se os professores exaustos e aproximarem-se de um esgotamento físico e mental pela preocupação pandemia, não poderão ajudar a si e aos alunos.

Significa que para se construir um ambiente escolar mais seguro, precisa-se, de acordo com as autoras, de políticas educacionais que orientem o uso inteligente das tecnologias, priorize os mais vulneráveis e proteja educadores e alunos, estudando e direcionando as estratégias de ensino vendo a educação como espaço do saber fundamentado o trabalho docente que, em função da pandemia, pode comprometer o ensinoaprendizagem levando desgaste à educação, apreendendo que a educação exerce conforme Dias e Pinto (2019), forte influência na transformação da sociedade, reforça a capacidade crítica da sociedade e pode com inteligência aprender com a crise e transformar a sociedade, futuramente melhorar a educação.

Noutra visão, concebe-se, que a proliferação do CONVID-19, segundo Vieira e Ricci (2020), é uma questão de saúde pública, trazendo consequência 
econômicas, políticas e sociais, atingindo por decorrência o campo educacional provocando o isolamento social, atingindo conforme a UNESCO (2020), cerca de 1,6 milhões de crianças e jovens pelo fechamento de escolas, interrompendo, por conseguinte, as atividades escolares.

Esta situação levou às escolas ao debate sobre o uso das tecnologias de ensino remoto, de certa forma em caráter emergencial com a preocupação de disponibilizar ferramentas e dispositivos para a prática de ensino tipicamente a distância e de forma urgente treinar os professores para a utilização desses dispositivos, visto que para continuar as atividades curriculares teria que se utilizar de plataformas digitais para não perder completamente o ano letivo.

Isto leva as escolas e professores a repensar o fazer didático adotando preceitos sobre o que fazer e como fazer para manter o nível de ensino, o que provocou a necessidade de se replanejar as atividades didático-pedagógicas levando a escola e os professores a uma reflexão sobre os conteúdos curriculares e a prática pedagógica, para, com o uso da tecnologia, dar suporte à aprendizagem do aluno, reconhecendo que um número considerável de alunos tem dificuldade de acesso à Internet, o que tornou mais difícil o papel do professor frente a pandemia.

Embora as escolas estejam fechadas prejudicando milhões de estudantes, há de se entender que esse fechamento é uma medida necessária para evitar e conter o vírus, sobretudo, porque as aulas presenciais provocam aglomeração, é um ambiente natural para a proliferação e contágio do vírus, o que se faz necessário medidas de isolamento social e a reflexão sobre como conduzir a aprendizagem dos alunos com o uso da tecnologia, o que também leva ao processo de ressignificação da educação e como contextualizá-la através do uso de aplicativos digitais.

Nesse sentido, pode-se afirmar que a pandemia trouxe forçosamente uma revolução didático-pedagógica exigindo a utilização de plataformas digitais, valorizando a modalidade de ensino a distância, agora atingindo não apenas o ensino superior, mas o ensino básico e médio e cursos profissionalizantes, em função da emergência imposta pela pandemia, deixando alunos, professores e as escolas atônitas tendo de replanejar as atividades escolares para se adequar a essa nova realidade.

Vale ressaltar que a maioria das plataformas digitais utilizadas por professores e alunos são de uso grátis 
como, o Google Classroom, o Zoom e Teames da Microsoft, por exemplo, que permitem a organização de disciplina, uso de vídeos, exibição de slides, acompanhamento de frequência e discussão com os alunos, o que facilita a interação de aluno e professor e ajuda o processo de aprendizagem., também interferindo no processo de integração do processo educativo, conduzindo o professor a se adaptar a novos métodos de ensino.

Implica na adaptação de uma nova cultura de ensino-aprendizagem e conteúdo, migrando-se da escola presencial para a não presencial, instigando principalmente o professor a adotar uma nova cultura de ensino sendo levado a incorporar novo jeito de ensinar, mudando, por decorrência, sua prática pedagógica, agora se utilizando de softwares e computadores, produzindo mudanças sociais e de hábitos de alunos e professores pelo uso do processo cibernético.

O fato é que a pandemia deixa sua marca negativa para a educação, porém, criou a condição de se repensar a educação, exigindo um novo planejamento para adequar o sistema de educação à realidade determinante pelo Covid-19, exigindo medidas emergenciais para apropriar o sistema de ensino-aprendizagem à realidade da pandemia, provocando mudanças também emergenciais para evitar a descontinuidade da educação brasileira e no mundo.

Interferiu diretamente nas atividades pedagógica levando às escolas a um regime especial de aulas remotas, visando, notadamente, a proteção à saúde de professores e alunos utilizando as plataformas digitais para viabilizar as atividades escolares e o acesso ao aluno à aprendizagem, embora se reconheça que grande parte dos estudantes possam ter dificuldade de acessar os aplicativos e a própria Internet durante o distanciamento social.

Mesmo assim, há de se considerar que o uso das mídias e dispositivos digitais foi uma alternativa viável, pelo menos em parte, para assegurar o direito à educação, conforme preconiza a Constituição Federal de 1988., embora as pesquisas demonstrem que $53 \%$ da população brasileira, incluindo professores e alunos, sentem medo e se considera vulnerável diante do vírus, o que por si, justifica as aulas não presenciais.

Nessa situação, é preciso se fazer uma revisão urgente no modelo educacional brasileiro mediado pela tecnologia de forma a permitir a sequência normal do ensinoaprendizagem de modo assertivo, 
incluindo treinamento de professores sobre o uso da tecnologia, podendo-se adotar um processo hibrido. Isto é, um modelo presencial paralelo ao remoto para evitar a descontinuidade do processo educativo e do processo de ensino-aprendizagem, dando-se suporte e sustentabilidade à educação.

Urge, por outro lado, pensar na integridade do estudante, principalmente daqueles que por qualquer motivo tenham dificuldade de adquirir computador e ter acesso aos dispositivos digitais, requerendo, por conseguinte, uma reflexão sobre a demanda do ensino.

Ademais deve-se considerar que a pandemia veio demonstrar uma realidade danosa à educação, especialmente no que diz respeito a estrutura social, não apenas pelas dificuldades inerentes a falta de condições do aluno para adquirir, por exemplo, um computador ou ter acesso à Internet, mas, porque muitas crianças vão a escola para se alimentar, aproveitar a merenda escola, por muitas vezes, não ter de que se alimentar em casa e, isso é uma realidade cruel.

Deve-se entender, por outro lado, que a escola como ambiente de aprendizagem é insubstituível que nesse momento, porém, é imprescindível manter o distanciamento social, tendo as aulas remotas como instrumento para continuar o processo de ensinoaprendizagem e a ação educacional, mesmo a distância.

Deve-se considerar que no momento, a prioridade deve ser a manutenção da saúde de professores e alunos e preservação de vidas que podem ser ceifadas pelo Covid-19, devendo-se, entretanto, estar atento aos efeitos da pandemia que diretamente afetam a educação, que, por consequência, pode afetar o desempenho de professores e alunos e da aprendizagem, o que naturalmente, requer uma avaliação do processo educativo, tendo como estratégia as aulas remotas.

Deve-se levar em consideração que as aulas não presenciais podem concorrer para a evasão dos alunos. Compete ao professor buscar a maior integração possível com os alunos estimulando-os a continuar a frequentar as aulas não presenciais, evitando que a situação trazida pela pandemia se agrave ainda mais, garantindo a assiduidade dos alunos e, assim, diminuir os efeitos pandêmicos à educação, evitando o colapso da educação e da escola.

Mesmo se reconhecendo que as aulas presenciais são essenciais para a integração do professor e aluno, há de se reconhecer que em momento de pandemia, as redes digitais são importantes para que se dê continuidade 
ao processo educacional, pois é a alternativa para se substituir as aulas presenciais. Um poio e suporte para os profissionais da educação que devem usa-las o mais democraticamente possível, fazendo com que o aluno participe das aulas da maneira mais ativa possível.

Deve-se, entretanto, levar em conta que no processo de aulas remotas, conforme situa Wills et. al., 2014), os estudantes mais vulneráveis são os alunos de baixo nível socioeconômico, o que naturalmente requer que a escola monitore o acesso dos alunos às aulas não presenciais avaliando concomitantemente aa relação ensinoaprendizagem, acompanhando o desenvolvimento do aluno, evocando a participação e o acompanhamento das famílias para também ajudar e acompanhar o desempenho do professor e do aluno para, se não eliminar, pelo menos, reduzir a defasagem ente ensino aprendizagem.

Nessa perspectiva, vale ressaltar que uma grande parte dos estudantes moram na zona rural, e, por decorrência, têm dificuldade de acesso a uma Internet de qualidade, e por isso têm a aprendizagem prejudicada, situação que se agrava pela falta de condições financeira de partes dos alunos, por não poder adquirir, por exemplo, um computador que é essencial para as aulas remotas, podendo-se também entender que as aulas remotas podem trazer desigualdades de aprendizagem, também pela falta de qualidade da Internet, principalmente, na zona rural.

É preciso se considerar que quando a confecção é através do celular, o professor precisa adequar o conteúdo de acordo com a capacidade de armazenamento do aparelho, o que aumenta ainda mais a dificuldade do professor o conteúdo das aulas conforme o tamanho da capacidade do celular, o que também pode prejudicar a aprendizagem do aluno e o desenvolvimento da estrutura curricular, podendo por necessidade esticar o ano letivo, mesmo porque a educação não pode parar.

Nesse sentido, embora os dispositivos digitais tenham contribuído para a sequência do ano letivo, faz-se necessário se criar estratégias para minimizar as dificuldades dos alunos principalmente de baixa renda, buscando-se ofertar atividades pedagógicas paralelas para atender as necessidades dos alunos num esforço coletivo de educadores e escolas para, no mínimo, evitar desigualdades na aprendizagem dos alunos;

É, preciso, por outro lado, organizar as atividades pedagógicas 
conforme as necessidades do aluno, incentivando-o a cumprir a rotina de atividades não presenciais, pelo menos até quando durar a pandemia, em pressão para não estressar o aluno e fazer com que ele não perca o foco nos estudos, requerendo também a participação ativa da família, o que se torna essencial para o aprendizado do alunado.

Deve-se levar em conta que pela baixa escolaridade muitas famílias terão dificuldade de acompanhar o desenvolvimento e desempenho dos filhos, requerendo do professor maior atenção para orientar os pais e os alunos sobre as tarefas escolares, estimulando pais e alunos a se familiarizarem com os dispositivos digitais para suavizar a perda de aprendizado e manter o aluno ativo e disposto a enfrentar os desafios que a pandemia impôs, aprendendo a utilizar os aplicativos nas aulas não presenciais, mediadas e monitoradas pelo professor.

De outra forma, pode-se afirmar conforme aponta Silveira (2020), tem como obrigação manter o vínculo com o aluno não foi esquecido e que, mesmo com as aulas remotas ele continua elemento vivo da escola. Está apenas afastado do convívio presencial continua sendo importante para que a escola e a educação sobreviva às intempéries da pandemia, alimentando a esperança de volta às aulas presenciais.

É, preciso então, se readequar o modelo de educação brasileira, levandose em consideração que a situação imposta pela pandemia que segundo a Fundação Carlos Chagas - FCC, (2020), exige por um lado, repensar os conteúdos e as práticas pedagógicas adequadas para o contexto virtual e, de outro, requer discutir atividades avaliativas considerando a diversidade de situação e condições de vida em que se encontram os estudantes dos diversos níveis de ensino e que ainda de acordo com a FCC, não se trata apenas de transpor práticas que antes eram presencialmente para contextos virtuais, havendo clareza de que no pós pandemia o cotidiano escolar não será o mesmo, é o que acham $65,6 \%$ dos professores pesquisados.

A realidade é que a tecnologia tem influenciado a sociedade e, dentro dessa, o sistema educacional, hoje, conforme aponta Fonsêca, et. al. (2020), totalmente inserida na sociedade, fazendo parte das ações cotidiana, onde se insere a educação, levando professores a quebrar paradigmas tradicionais, inserindo uma cultura cibernética, sobretudo, no sentido de adequar e reorganizar as práticas pedagógicas. 
Para Barbosa, Viegas e Batista (2020) essa ainda uma questão polêmica em nível educacional, porquanto os professores encontram dificuldades na adequação dos recursos tecnológicos ao contexto das atividades pedagógicas cotidianas, tendo do outro lado, alunos familiarizados com o dispositivo digital.

Todavia, não obstante essa afirmativa, pode-se consignar que a realidade não é bem assim, muitos alunos nem sequer tem acesso a um computador ou a uma Internet de qualidade principalmente nas famílias de pouco poder aquisitivo que muitas vezes nem tem o que comer, muito menos a condição de um computador que embora seja necessário está fora do alcance, principalmente nas classes $\mathrm{C}$ e D da população brasileira.

Por outro lado, não há dúvida, que com a suspensão das aulas presenciais, não há dúvida que a tecnologia seja uma necessidade premente, uma condição imperativa para a continuidade do processo de ensinoaprendizagem, possibilitando, segundo Santos, Alves e Porto (2018), a democratização do conhecimento, o que não deixa de se exigir da escola o isolamento social como prevenção da pandemia que é uma questão social de saúde.
Isso significa que a escola tem o dever de ajustar suas atividades ao contexto pandêmico, sobretudo, para proteger seus alunos e seu próprio contexto, o que denota a prática da cidadania e respeito aos seus alunos e professores, salvaguardando a saúde de seus profissionais e de seu alunado, seguindo os protocolos de segurança e princípios sanitários para preservar a reputação de seus profissionais e sua postura na sociedade.

Há de se conceber que o ensino remoto conforme aponta a Fundação Carlos Chagas (2020), é uma medida temporária em relação a educação e as atividades pedagógicas, interferindo no planejamento do professor e da escola exigindo uma readaptação das estratégias pedagógicas influenciando o processo educativo da aprendizagem, forçando mesmo de forma intempestiva, repensar uma nova forma de ensinar, assumindo a tecnologia como um instrumento pedagógico, permitindo ao aluno a ser criativo e tornar o aluno um sujeito ativo do conhecimento e de sua aprendizagem.

Todavia, há de se considerar que nem todos os alunos têm acesso a Internet e assim como o próprio ensino digital pode apresentar falhas prejudicando o sistema de ensino, e, concomitantemente, a educação, o que 
aumenta o desafio dos professores e alunos, principalmente das escolas públicas que muitas vezes não tem capacidade de se adequar às condições ideias para atender a demanda digital dos alunos, ocasionando defasagem entre o ensino e a aprendizagem, provocando insegurança para a escola / professores e alunos.

O certo é que a educação on-line ou presencial deves ser vista como um todo, envolvendo como protagonistas o professor, o aluno, valorizando os atores do processo educacional onde $\mathrm{o}$ professor assume o papel de mediador valorizando o conjunto de conhecimentos e, na prática, potencializar as ações dos alunos, mediando as interfaces do aluno com os dispositivos digitais, independente ou não das aulas presenciais.

É preciso que se entenda que a pandemia atingiu todos os níveis da educação brasileira, trazendo contornos que provavelmente mudará de forma intensa o jeito de aprender e de ensinar, onde o ambiente educacional passa por transformações levando a escola a pensar de forma particular suas prioridades para antes de tudo aliviar a pressão dos professor e alunos frente a pandemia do Corona Vírus, que sem contar a pressão psicológica, afeta diretamente o processo educacional, os alunos e professores, provocando por decorrência desigualdade do aprendizado, levando professores e alunos a buscarem saída para não perder o ano letivo.

Isto leva a um repensar profundo sobre a educação brasileira, refletindo-se sobre a educação levantando a preocupação de como apoiar os alunos e professores evitar estresse de professores e alunos, conduzindo os professores, principalmente, a imaginar estratégias para facilitar o ensino-aprendizagem impondo à escola uma tomada de decisão sobre como apoiar alunos professores salvaguardando os preceitos da educação, mantendo um ambiente saudável para minimizar os efeitos da pandemia, nocivos não apenas para professores e alunos e da própria educação.

O fato é que em meio a situação caótica trazida pela pandemia do Corona Vírus, a educação não presencial tem servido para novas descobertas primordiais na transmissão e aquisição do conhecimento e a interação de professores e alunos, visando, sobretudo, o fortalecimento da aprendizagem, cabendo a escola articular suas ações com professores e comunidade escolar para o cumprimento de medidas preventivas contra o covid-19, agora com o uso das tecnologias remotas que 
têm contribuído para a manutenção das aulas, tipicamente a distância.

Nesse contexto, há de se conceber que a tecnologia tem sido uma aliada da educação brasileira, constituindo-se um ambiente de aulas virtuais, proporcionando a interação entre professores e alunos através de videoconferência, palestra em tempo real, alinhando, mesmo que com dificuldades, a intenção educacional às necessidades dos alunos e vice-vessus, permitindo a troa de informações através de envio e recebimento de mensagens mantendo professores e alunos ativos quanto ao processo educativo, por meio de postagens de vídeos, materiais de instruções e recomendação de estudo via Internet.

Requer, entretanto, que professores e alunos se empenhem para, com inteligência usar os aplicativos digitais para intensificar a aprendizagem e, no caso do professor, ter a habilidade para envolver os alunos no processo digital de forma interativa e produtiva otimizando o conhecimento e a aprendizagem de maneira também otimizada, articulada com as necessidades do aluno, principalmente, visando uma educação com a maior qualidade possível, apesar das dificuldades que professores e alunos têm sentido na operação das mídias digitais.

Pode-se de outra forma mencionar que a pandemia também impôs manifestações econômicas, políticas e sociais, implicando na tomada de consciência de que no momento de pandemia é preciso que haja e se desenvolva o espírito de colaboração coletiva, visto que o Corona-Vírus, atinge toas as classes sociais independente do status ou poder econômico, o que requer uma visão global de toda sociedade, que segundo Lucena (2019), reforça a necessidade de resistir à crise provocada pela pandemia, exigindo da sociedade o compromisso ao combate do covid-19, o que representa um ato educacional e a expressão da cidadania.

Pode-se então afirmar que se proteger e proteger os outros da pandemia é um ato de educação, de cidadania que se reflete na postura a sociedade e no caso da educação, aliar a prática pedagógica numa visão de futuro indispensável à educação e ao processo escolar e interação entre o ensinar e aprender.

Urge por outro lado, que a escola se preocupe com a capacitação de seus profissionais para que eles possam de forma substantiva apender a operar com segurança os dispositivos digitais, 
notadamente para dar consistência e qualidade de sua prática pedagógica, subsidiar e orientar os alunos de como utilizar os dispositivos de forma a não ter dúvida de operacionalização das plataformas digitais, e, assim, poder otimizar a aprendizagem.

Esse processo de otimização da aprendizagem e interação entre professor aluno, pressupõe que haja um espaço colaborativo com apoio das mídias digitais e sociais que permitam interrelações entre o aluno e o processo educativo incorporando a educação como uma atividade que precisa ser internalizada como atributo da própria cidadania que se reflete nos deveres e direitos do ser humano, fundado na própria educação como estratégia do desenvolvimento do ser humano em todos os níveis e idade.

Com relação aos dispositivos voltados para aulas remotas, é preciso que se tenha o cuidado no que se posta, para que não haja dúbia interpretação das mensagens, pois, as palavras são como uma flecha, tem que acertar o alvo, visto que em não acertando pode causar desconforto e prejudicar o entendimento provocando um feedback que não corresponde, por exemplo, a intencionalidade do professor e/ou do estudante.
É preciso se entender que a comunicação é uma ferramenta para fazer as pessoas entenderem uma mensagem sem possibilidade de dupla interpretação, o que significa que o professor, em sua práxis, precisa pensar e planejar detalhadamente sua prática pedagógica, de modo que o aluno possa alcançar o conteúdo de maneira clara e racional e assim, ampliar e aprofundar seus conhecimentos de acordo com os preceitos e dinâmica educacional, ampliando, não raramente sua capacidade de pesquisa e trazer coisas novas para discussão em sala de aula, mesmo que virtual.

É papel do professor incentivar o aluno a utilizar a tecnologia digital para ir em busca do conhecimento, e, consequentemente, do desenvolvimento do aluno, constituindo o ambiente virtual em espaço de discussão e compartilhamento do conhecimento abrindo espaços para tirar dúvidas e, consubstanciar a prática didáticopedagógica do professor, o que podemos chamar de processo colaborativo entre o estudante e o professor, pressupondo-se ser também o desejo da escola de modo a propiciar um ambiente favorável para a aprendizagem e a venda da imagem da escola em consonância com seus objetivos de instruir e educar seu alunado. 
Assim, há de se compreender que a tecnologia aplicada à educação, é uma ferramenta colaborativa que ajuda o poder de inovação e da criatividade de professores e alunos se inserindo na educação como um instrumento, não apenas para transmitir conhecimento, mas, para direcionar a prática pedagógica do professor e a aprendizagem do aluno, principalmente, em tempo de pandemia, o que reforça o pensamento de Santinello (2013), de que a educação virtual pode contribuir para a democratização do ensino e, concomitantemente, com a educação.

Pode-se salientar que a pandemia do Corona Vírus, sérvio também para reforçar a cooperação e disseminação do conhecimento entre professor e aluno, ampliando a capacidade de mobilização da comunidade escolar com o fito de superar os males da pandemia, e preservar, mesmo que com dificuldades, o processo de educação, agravado, porém, inicialmente pela falta de prática de usabilidade da tecnologia e dispositivos digitais, que agora já de torna comum para professores e alunos, embora a Internet tenha, praticamente, se tornado a sala de aula.

Nesse sentido, o professor se apropria das mídias digitais para gerar novas possibilidade de aprendizagem, o que requer que o educador deve estar ligado e conectado a essas mídias se desafiando para redirecionar as dimensões do ensino para concretizar sua prática pedagógica criando e recriando conteúdos e métodos orientando o estudante como se apropriara do conhecimento e sustentar sua aprendizagem e explorar o potencial cognitivo do aluno, delineando o percurso da educação não presencial e humanizar as experiências durante a pandemia.

É preciso, por outro lado, que as instituições educativas se preocupem com a formação digital do professor, visto que muitos ainda não têm domino da linguagem computadorizada, e, se assim o for, podem não cumprir seu papel de instrutor e de professor deixando carência, sendo, por decorrência ineficiente no contexto educacional, desconstruindo sua prática e sua imagem como educador e, concomitantemente, da escola e da educação.

Significa que os institutos de educação precisam aperfeiçoar seus docentes para lidar eficazmente com os aplicativos de aulas remotas, o que requer treinamento, também para lidar com as novas dimensões da educação e assumir o compromisso com a saúde dos discentes e com o desempenho profissional com ênfase no aprendizado 
do aluno fazendo a transposição didática, isto é, transformar conteúdos científicos e conhecimento cotidiano, sem se afastar da realidade do aluno, da perspectivas da escola e da educação.

Deve-se entender que a educação é um direito universal onde o cidadão, no caso o professor, em meio a pandemia, deve agir forma fraterna, buscando e dando aos discentes o direito a liberdade e de autonomia para sse manifestarem a respeito das aulas remotas no sentido de adequar os métodos de ensino. Ou seja, o professor deve ouivird os alunos, sobretudo, para adeqiuar as ferramentas de ensiono à realidade do estudante, para, no mínimo, reduzir a questão da não aprendizagem, visto que muitos alunos têm diiculdade de manejar os dispositivos e até mesmo de compreensão dos assuntos trabalhados, principalmente porue estão acostumadas à prática interativ das auilas presenciais.

Significa, conforme Silva (2020), que o professor além de ser um bom transmissor, precisa ser um bom ouviinte. Precisa ouvir a concepção e a precepção do aluno sobre as aulas remotas, não apenas para dar qualidade ao esino, mas, e, principalmente, para, se for necessário, redirecionar seu planejamento didátio-pedagógico, de modo a satisazer as reivindicações dos discentes e dar qualidade e eficiência ao ensino com fluxo primordial na educação e assim fazer a escola cumprir seu papel social.

\section{FUNÇÃO SOCIAL DA ESCOLA FRENTE A PANDEMIA}

A função da éducação não é apenas instruir, mas, cuidar do desenvolvimento das pessoas de maneira holística, isto é, como um sistema integrado, onse se uma peça falhasr influencia fortemente o resultado final. Assim, há de se entender que se o professor falhar a escola falha, se o aluno fracassar a escola fracassa.

Significa que a escola como ente educaativo não pode, nem deve apenas instuir, mas, cuidar da formação de seus alunos, no caso da pandemia, trazendo em seu bojo as contradições, ambiguidades e conflitos, mediando e entendendo que a educação sempre esteve a serviço da sociedade, assimilando o entorno de quem e de que é feito a educação, levando em conta conforme aponta Cavalcante (2007), as diferentes concepções de homem, sociedade e finalidades educacionais.

No que tange a pandemia, o papel social da escola deve enfrentar a pantemia como o problema inerente à educação, compresendendo que lcomo instituiçao social, é seu dsever se organizar de modo a instruir seui corpo 
docente e discente como lidar com a pandemia, tomando todas as precausões possíveis para evitar os efeitos do vírus, salvaguardando a saúde dos profesores e alunos, respeitando as regras sanitárias e a recomendação dos órgãos que cuidam da saúde do povo brasileiro.

Nessa visão há de conceber que seu papel na sociedade é de compreender a realidade onde está situada, com o pensamento de formar cidadãos conscientes dos seus direitos e deveres, autônomos e reflexivos, capazes de compreender a realidade em que vivem, aptos para participarem da vida social, não só da realidade local, mas até do país, contribuindo para uma sociedade livre de preconceitos, buscando a inclusão social como preceito educativo, onde o ser humano possa viver com dignidade, respeitando a si e aos outros, como por exemplo, o isolamento social que preconiza o respeito pela sociedade às normas de combate ao Corona Vírus.

Deve preconizar e disseminar o respeito às normas sanitárias em sua totalidade se tornando um ambiente para promover o desenvolvimento e educar as pessoas, tendo a obrigatoriedade de trabalhar todo o contexto da pandemia, protegendo sua comunidade, onde se inclui professores e alunos e suas famílias para evitar o contágio da pandemia, assumindo-se como responsável por todos que estão à sua volta e no contexto da sociedade onde está inserida, assimilando, conforme ponta Tedesco (19950, com profundidade o processo de mudança social, que no momento exige responsabilidade de transformar valores em concepção sobre o combate a pandemia.

Assim, a escola como lócus do processo de formação deve desenvolver a capacidade de integração devendo, por exemplo, a comunidade pensar sobre os reflexos da pandemia no seio da escola e da sociedade a quem serve, abraçando a ideia de que a comunidade escolar é também um instrumento político para apoiar as causas nobre combatendo os desmandos, nesse instante de ideologias negacionista sobre os efeitos da situação pandêmica em que o Brasil vive, absorvendo conforme menciona Freitas (2006, p. 34), que o homem, “é o ser político capaz de questionar, criticar, reivindicar, ser militante e engajado na transformação da ordem social".

Nesse contexto, não há como negar que a escola como entidade educativa, precisa socializar um saber sistematizado, vendo a educação como um patrimônio universal, fazendo com que esse saber seja criticamente apropriado no contexto pandêmico que ora se vive no Brasil e em todo o mundo, 
cabendo-lhe fazer a interligação e apropriação do saber como fonte de aprendizagem dos alunos e dos profissionais envolvidos com a educação, discutindo criticamente a realidade da educação frente a pandemia, rompendo as formas alienantes que não estão a favor da saúde de seus membros e da sociedade.

A escola, assim como a educação deve entender que o homem é fruto da prática social coletiva, o que requer identificar o contexto histórico da pandemia, levando-a a recuperar e redimensionar as dimensões da pandemia, agindo de forma consciente para também redimensionar os valores e motivar as pessoas a desenvolver habilidades para enfrenar os efeitos da pandemia, reconhecendo que conforme situa Aranha (1996), que os valores estão na base da práxis educativa.

Deve considerar que em função da crise pandemia que se estar vivendo, torna-se necessário refletir sobre a prática educativa refletida e que se reflete na sociedade, cabendo-lhe $\mathrm{o}$ esforço para vencer as dificuldades de alunos e professores frente a pandemia e sobre os aspectos positivos e negativos de aulas remotas em relação a aprendizagem dos alunos e a interação professor-aluno e em relação a formação do aluno, apreendendo que a educação é uma ação transformadora da sociedade, encarando a pandemia como um processo descontextualizado da educação, que precisa ser combatido com eficiência e eficácia.

A escola então, deve entender que um de seus objetivos primordiais é orientar e desenvolver políticas capazes de elevar a aprendizagem numa perspectiva cotidiana e para o futuro, assimilando que a educação consiste em socializar saberes que se aplique no cotidiano e no contexto social, compreendendo a sociedade como um sistema, cujos problemas precisam ser resolvidos, evocando o contexto sociocultural do ambiente do aluno e da própria sociedade, onde a escola se insere, o que também significa adotar uma prática pedagógica capaz de facilitar o desenvolvimento de conhecimentos contextualizado à práxis social.

Cabe a escola compreender que o ensino-aprendizagem é um processo que envolve a mobilização e interação dos alunos. Significa que a escola e os educadores primem pela interação dos alunos, de modo que eles possam interagir e participar ativamente da escola e do processo educativo, enteando-se que para que haja mudanças significativa, segundo Paulo Freire (1991), há necessidade de decisões 
políticas-administrativa e pedagógica, desde o aluno aos membros da comunidade.

É preciso, por outro lado, se entende que a escola é também um ambiente social, o que está expresso no pensamento de Alarcão (2001), ao afirmar que a escola sem pessoas seria um edifício sem vida. Isto é, quem torna a escola viva são as pessoas: alunos, os professores, os funcionários, bem como os pais de alunos que com ela interagem.

Significa que a escola precisa envolver e engajar todos que fazem parte da comunidade escolar, apregoando a necessidade de um trabalho coletivo, participativo e solidário comprometida com o processo educativo e humanizado, o que está de acordo com a visão de Anastasiou (2002, p. 97) ao afirmar que: “a educação é um processo de humanização". Ou seja, processo pelo qual se possibilita que as pessoas se insiram na construção da sociedade humana.

Nessa perspectiva, a função da escola e da educação é inserir os cidadãos no processo educacional, no caso da pandemia, cabendo a escola educar a comunidade escolar, ou seja, professor, funcionários, alunos e a comunidade, promovendo a educação em todos os níveis sobe os riscos e a prevenção do Corona Vírus para preserva a saúde e saber como se proteger diante surto epidêmico que hoje vive a sociedades brasileira, e, assim, amenizar os perigos de contágio.

Nesse sentido, o papel da escola fazer com que alunos professores e a sociedade que lhe estar ao seu redor reflitam sobre os efeitos da pandemia e desenvolvam hábitos saudáveis que possam contribuir para o combate ao vírus, apreendendo que a educação é um reflexo da sociedade. Ou seja, se concretiza quando se enfrenta as demandas do contexto, o que no caso da pandemia, um desafio. Um processo para enfrentar desafios e promover mudanças e a prática da cidadania.

Assim, pode-se considerar que um dos papéis sociais da escola e da educação é preparar as pessoas para enfrentar os desafios vivenciando experiências e orientar professores, pais e alunos, para com sobriedade enfrenar os desafios que é imposto pela situação atual, entendendo que a comunidade escolar precisa de equilíbrio e serenidade para enfrenar o surto do Corona Vírus, buscando soluções para o Corona Vírus da sociedade brasileira, entendo que a escola é um centro do conhecimento que influencia a capacidade de pensar, de tomar iniciativa plausível para solucionar problemas. 
Isto, por outro lado, quer significar que a escola deve assumir o contexto da pandemia como uma possibilidade para educar e influenciar as pessoas a se cuidar, compreendendo que em uma sociedade em crise, precisa-se ter equilíbrio para não deixar a população em pânico, se alastra e tomar conta da vida e da sociedade.

Em síntese, é preciso que a escola se eduque e eduque as pessoas a conviverem com as adversidades, dissipando o medo para enfrentar as intempéries, além de motivar as pessoas para enfrentar as dificuldades com naturalidade, assumindo a responsabilidade social como um atributo próprio da educação, voltada para a conscientização das pessoas, assumindo-se como responsável pelo desenvolvimento da sociedade na qual está inserida.

\section{CONCLUSÃO}

A pandemia é um fenômeno que tem afetado o mundo assustando e pondo em pânico a sociedade e, por decorrência, atingindo de forma intensa à educação, fazendo-se adotar uma cultura cibernética como alternativa para a continuidade do processo educativo.

A verdade é que a pandemia mudou o jeito de se ensinar e de se educar trocando as aulas presenciais por aulas remotas, mudando o jeito de ensinar e de aprender, sem, entretanto, com a mesma imensidade das aulas presenciais.

O certo é que a pandemia trouxe forçosamente mudanças para $\mathrm{o}$ planejamento e prática pedagógica, levando professores e alunos a uma readaptação da realidade educativa, interferindo no jeito de ensinar e aprender, de repensar métodos e prática de ensino, exigindo uma nova maneira de inter-relações entre professor e aluno.

Em meio a pandemia não basta utilizar dispositivos digitais, requer que o professor e a escola estejam preparados para não só compreender, mas, estar prontos e conscientes para solucionar as dificuldades dos alunos, notadamente daqueles que demonstram maior dificuldade em aprender e a utilizar as mídias remotas, o que requer estar mais próximo do aluno.

Enfim, nesse momento é preciso que a escola mais do que antes, se preocupe com a conscientização dos alunos e familiares sobre os riscos e as consequências da pandemia, assumindose efetivamente como entidade educativa, também para minorar os efeitos da pandemia na educação, compreendendo que educar não é apenas instruir, mas, preparar o homem para com resiliência enfrentar os desafios 
com tranquilidade e reverter situações adversas em aprendizado.

\section{REFERÊNCIAS}

ALARCÃO, Isabel. Do olhar supervisivo ao olhar sobre a supervisão. In RANGEL, M. (Org.) Supervisão Pedagógica. Princípios e Práticas. São Paulo: Papirus. 2001.

ANASTASIOU, Lea das Graças Camargo Docência no Ensino Superior, São Paulo: editora Cortez, 2002. Coleção docência em Formação.

ARANHA, Maria Lúcia de Arruda. Filosofia da educação. 2.ed. rev. e atual. São Paulo: Moderna, 1998.

BARBOSA, A. M.; VIEGAS, M. A. S.; BATISTA, R. L. N. F. F. Aulas presenciais em tempos de pandemia: relatos de experiências de professores do nível superior sobre as aulas remotas. Rev. Augustus, v.25, n. 51, p. 255-280, 2020.

BRASIL, Ministério da Educação, portaria 343/20. Brasília (DF), MEC, 2020. , o Conselho Nacional de

Educação pela portaria 345//20. Brasília (DF), CDE 2020.

CAVALANTE, Maria do Socorro Aguiar de Oliveira. Qualidade e cidadania nas reformas da educação brasileira: o simulacro de um discurso modernizador. Maceió. EDUFAL, 2007.

DIAS, E.; PINTO, F. C. F. Educação e sociedade. Ensaio: Avaliação e Políticas Públicas em Educação, Rio de Janeiro, 2019. Disponível em $<$ https://doi.org/10.1590/s0104$40362019002701041><$ Acesso em 28.03.2021>.
FONSÊCA, Luçamara Beserra Holanda da. et. al. Perspectivas do ensino remoto na educação brasileira. VI Congresso Nacional de Educação. Maceió (AL), 2020.

FREIRE, Paulo. Pedagogia do oprimido: saberes necessários à prática educativa. 9 . ed. São Paulo: Paz e Terra, 1996.

FREITAS, H. C. L. A pedagogia das competências como política de formação e instrumento de avaliação. In VILAS BOAS, Benigna M. E. (Org.). Campinas: Papirus: 2006.

FUNDAÇÃO CARLOS CHAGAS. Educação em tempo de pandemia: São Paulo: FCC, 2020.

WILLS, Gabrielle et al. Os efeitos da atividade de greve dos professores na aprendizagem dos alunos nas escolas primárias sul-africanas. 2014. Tradução: Nadieje Maria Soares.

LUCENA, Carlos. Prefácio. In: SILVA JÚNIOR, João dos Reis et al (Org.). Das crises do capital às crises da educação superior no Brasil: novos e renovados desafios em perspectiva. Uberlândia: Navegando Publicações, 2019, disponível em

<https://www.editoranavegando.com/livroanped > <Acesso em 30.03.2021>.

MAIA, B. R.; DIAS, P. C. Ansiedade, depressão e estresse em estudantes universitários: o impacto da COVID-19.

Revista estudo de psicologia. Campinas, v. 37, 2020. Disponível em https://doi.org/10.1590/1982$0275202037 \mathrm{e} 200067<$ Acesso em 28.03.2021>.

MARTINS, Vivian; ALMEIDA, Joelma. Educación en tiempos pandémicos en Brasil. Disponivel em < 
http://lattes.cnpq.br/2839844705473657>

Acesso em 26.03.2021>.

SANTINELLO, Jamile. Tecnologias da

Informação e Comunicação (TIC)

aplicadas à formação do Gestor Escolar.

Guarapuava, (PR): UNICENTRO, 2013.

SANTOS F. M. F.; ALVES A. L.; PORTO

C. M. Educação e tecnologias:

Potencialidades e implicações

contemporâneas na aprendizagem. Revista

Científica da Fasete, v.12, n. 18, p. 44-61, 2018.

SILVA, José Aragão da. Educação no contexto da pandemia. Arapiraca: FRM, 2020.

SILVEIRA, Lecticia Maggi. Projeto educação não pode parar. Comitê Técnico da Educação do Instituto Rui Barbosa (CTE-IRB) Interdisciplinaridade. São Paulo: Instituto Rui Barbosa, 2020.

UNESCO - Organização das Nações Unidas para Educação, Ciência e Cultura. Educação e planejamento antecipado contra o aumento das desigualdades após COVID-19. Paris, 2020. Disponível em $<$ https://pt.unesco.org/news/comissaofuturos-da-educacao-da-unesco-apelaao-planejamento-antecipado-o-aumentodas.>. < Acesso em 28.03.2021>.

VIEIRA, Letícia; RICCI, Maaike, C.C. A educação em tempos de pandemia: soluções emergenciais pelo mundo. Florianópolis: Editorial do Observatório do Ensino Médio, 2020. 